\title{
Climatic characteristics of summer human thermal discomfort in Athens and its connection to atmospheric circulation
}

\author{
A. Bartzokas ${ }^{1}$, C. J. Lolis ${ }^{1}$, P. A. Kassomenos ${ }^{1}$, and G. R. McGregor ${ }^{2}$ \\ ${ }^{1}$ Laboratory of Meteorology, Department of Physics, University of Ioannina, Ioannina, Greece \\ ${ }^{2}$ School of Environment, The University of Auckland, Auckland, New Zealand
}

Correspondence to: A. Bartzokas (abartzok@uoi.gr)

Received: 17 September 2012 - Published in Nat. Hazards Earth Syst. Sci. Discuss.: Revised: 20 February 2013 - Accepted: 4 April 2013 - Published: 16 December 2013

\begin{abstract}
The climate characteristics of summer human thermal discomfort in Athens and its connection to atmospheric circulation are studied for the period 1954-2012. The human thermal discomfort is examined in terms of the Predicted Mean Vote (PMV) discomfort index for calm and light wind $\left(3 \mathrm{~ms}^{-1}\right)$ conditions. Its inter-annual variability is characterised by a significant increase from the middle 1980s to the end of the study period. The onset and the cessation of the discomfort period are found to take place around the beginning of July and the end of August respectively, but from middle 1980s the dates of onset and cessation have slightly moved earlier and later, respectively, leading to a longer summer discomfort period. The connection between human thermal discomfort and atmospheric circulation is studied by examining the distribution of discomfort cases across six objectively defined circulation types over Europe, based on Athens weather characteristics. High values of the PMV discomfort index are mainly associated with two typical high-summer pressure patterns with the intensity of discomfort depending on the pressure gradient over the Aegean Sea. On the contrary, low PMV discomfort index values prevail mainly on days typified by the other four circulation types, which are more frequent during May, June, and September.
\end{abstract}

\section{Introduction}

Greece is a popular destination for millions of tourists every year. Its natural beauty and famous archeological sites constitute the main tourist attractions. Greece possesses a Mediterranean climate, characterised by cool and wet winters and hot and dry summers. This type of climate mainly dominates the southern regions and coastal areas of the country including Athens, which attracts many tourists not only because of its sites of archeological interest but also because it offers transportation links to the islands of the Aegean Sea. During the last decades, Athens has experienced regional climate change along with strong urbanization; however a delayed summer temperature increase in the eastern Mediterranean relative to the western Mediterranean, due to the higher frequency of northerly winds from middle 1960s to middle 1980s (Metaxas et al., 1991; Bartzokas and Metaxas, 1991), is a feature of observed climate change in this region. The increase of the mean temperature observed for Athens started in the middle 1980s (Founda, 2011). Furthermore, the continuous process of urbanization and the associated urban heat island effect constitutes a second contributor to the local warming and modification of climate characteristics, especially in summer (Philandras et al., 1999).

Understanding human thermal discomfort characteristics for Athens can assist with climate risk management in the areas of tourism and health. Several studies have examined thermal discomfort in Athens by applying a range of thermal comfort indices noting that, at times, levels of discomfort can be severe and occasionally last several days (e.g. see Metaxas, 1970; Giles et al., 1990; Matzarakis and Mayer, 1997; McGregor et al., 2002; Pantavou et al., 2008; Nastos and Matzarakis, 2012; Vouterakos et al., 2012). In a study which identified significant changes in the climatology of the season of thermal discomfort in Athens, McGregor et al. (2002) suggested that a worthwhile line of research would be exploring the link between thermal discomfort and atmospheric circulation. The identification of the main atmospheric circulation characteristics associated with 
thermal discomfort can lay the basis for weather-based early warning systems for heat stress. Also, the study of the interannual variability and trend of thermal discomfort for areas like Athens is important in the context of the intensification of urbanization and ongoing climatic change, both of which may significantly affect discomfort levels, the duration of the discomfort period and the connection between discomfort levels and atmospheric circulation. The present study is an extension of the one of McGregor et al. (2002), as it examines further the characteristics of the inter-annual and intra-annual variability of thermal discomfort in Athens (discomfort levels, dates of onset and cessation and discomfort duration) for a longer time period and, moreover, investigates the connection between levels of discomfort and atmospheric circulation patterns.

\section{Data and methods}

The design of empirical indices for the assessment of human thermal discomfort was one the main research efforts in biometeorology during the 20th century. The effective temperature and the discomfort index were two widely known indices designed for this purpose (Hougten and Yaglou, 1923; Thom, 1959). These indices have been applied in many biometeorological studies (e.g. Jauregui, 1991; McGregor, 1995a, b; Mavrakis et al., 2012). More recently there has been a tendency for empirical indices to be replaced with more complex biophysical models, which simulate the exchange of heat between individuals and the environment based on an evaluation of the human energy balance equation with physiological parameterizations representing thermophysiological processes (e.g. Fanger, 1972; Hoppe, 1993; McGregor, 2011). One of the human thermal comfort indices based on the energy balance approach is the Predicted Mean Vote (PMV) (Fanger, 1972). PMV represents on a thermal sensation scale the predicted mean vote of a large population exposed to a given set of ambient conditions and is a good predictor of mean responses for sedentary individuals wearing clothing suited for temporally constant and spatially uniform environments (McGregor et al., 2002). It is based on the difference between internal heat production and heat loss to the actual environment for a person kept at the comfort values for skin temperature and sweat production at the actual activity level (Fanger, 1972).

Recently, Jendritzky et al. (2012) introduced a new index named the Universal Thermal Climate Index (UTCI), which is defined as the isothermal air temperature of a reference condition that would elicit the same dynamic response (strain) of Fiala's multi-node human physiology and thermal comfort model (Fiala et al., 2012). Blazejczyk et al. (2012) compared UTCI values with various thermal indices that provide temperature as an output value arguing that an equivalent temperature makes the evaluation of thermal perception by the public more comprehensible. They estimated linear regression slope and $R^{2}$ coefficients between UTCI and about 20 other well-known indices. For the "simple" indices, based on meteorological variables only (e.g. heat index, Humidex, wet bulb globe temperature), they found very low coefficients (slope $<0.70$ and $R^{2}<0.50$ ), while for the thermophysiological ones (e.g. physiological equivalent temperature, perceived temperature, standard effective temperature) they found very high coefficients (slope near unity and $R^{2}>0.95$ ). For PMV, which does not provide an equivalent temperature as output, the relation with UTCI is described by $R^{2}$ only, which is found to be 0.98 , the highest amongst all indices considered. Taking into account (i) the high $R^{2}$ between PMV and the newly developed UTCI, which is considered applicable for a wide range of climate conditions, and (ii) the fact that the present work is an extension of the work of McGregor et al. (2002), who used the PMV, we consider the application of the PMV index to the analysis of atmospheric circulation thermal comfort associations valid.

In the present work, PMV is calculated for Athens at 12:00 UTC, i.e. 14:00 LT (15:00 summer time) (hereafter 14:00), for the warm period of the year (1 May-30 September, hereafter summer) over the $59 \mathrm{yr}$ period 1954-2012 $(153 \cdot 59=9027$ cases). The WINCOMF program (Fountain and Huizenga, 1995) is utilized, which requires input values of air temperature, humidity mixing ratio and atmospheric pressure. The original data used are daily values (14:00) of air temperature, relative humidity and atmospheric pressure at the National Observatory of Athens, Greece, for the above period. Mixing ratio is calculated from atmospheric pressure, relative humidity and air temperature, using the ClausiusClapeyron equation. PMV is calculated considering a human metabolic rate of 1 met $\left(58 \mathrm{Wm}^{-2}\right)$ and 0.5 clothing units (ASHRAE Standard 55 summer). The above metabolic rate and clothing level correspond to a lightly clothed person sitting for example in the outdoor environment of a café, sheltered from the sun. PMV values of -2 and +2 are defined as the thermal discomfort thresholds because, for values of PMV $\geq 2$ or $\leq-2$, about $75 \%$ of people do not feel comfortable (Fanger, 1972). Two ventilation states are considered, namely calm and light wind conditions corresponding to a wind speed of $0.1 \mathrm{~ms}^{-1}$ and $3.0 \mathrm{~ms}^{-1}$ respectively. A wind speed of $3.0 \mathrm{~ms}^{-1}$ is considered as the threshold beyond which wind becomes a nuisance factor (de Freitas, 1990).

The variability of thermal discomfort in Athens is examined in terms of the inter-annual variation of the following: (i) the mean summer 14:00 PMV values and (ii) the frequency of summer discomfort days at 14:00. The seasonality of thermal discomfort is studied by examining the intraseasonal (1 May-30 September) variation of the $59 \mathrm{yr}$ mean daily 14:00 PMV values as well as the number of discomfort cases for each summer day during the $59 \mathrm{yr}$ period. Also, the onset and cessation of the discomfort period for times when PMV $\geq 2$ are considered. The onset/cessation of the discomfort season is defined as the date when there was/was no longer 3 or more consecutive days with a PMV greater than or equal to a value of 2 at 14:00. 
Finally, the connection between human thermal discomfort and atmospheric circulation is studied by examining the distribution of discomfort cases across six objectively defined circulation types over Europe, based on Athens weather characteristics, for the warm period of the year. This type of approach, where the value of environmental variables (PMV index values in this case) is considered for a range of circulation types determined a priori, is often referred to as the circulation to environment approach in synoptic climatology (Yarnal, 1993). The circulation types used in this study have been defined by Kassomenos et al. (2003), who applied a classification scheme based on factor analysis and $k$ means cluster analysis on both (i) $2.5 \times 2.5$ grid point sea-level pressure values over Europe and (ii) meteorological observations over the Athens area. As the circulation types were defined for a period only up to 1999 , this part of our study is limited to the sub-period 1954-1999 comprising $46 \mathrm{yr}$.

\section{Results}

The inter-annual variations of the mean summer (14:00) PMV values (discomfort intensity) and the frequency of summer discomfort (PMV $\leq-2$ and $P M V \geq 2$ ) days (discomfort frequency) are presented for calm and light wind conditions in Figs. 1 and 2. It is seen that the features of the "discomfort climatology" in Athens are the considerable inter-annual variability and the positive linear trends (statistically significant at $95 \%$ confidence level - Mann-Kendall test) for mean summer PMV values (Fig. 1) and the number of days with PMV values greater than 2 (Fig. 2). Noteworthy is that strong upward trends in discomfort intensity and frequency occur after the early 1980s. Specifically, the mean summer PMV values, for calm conditions, in general, range from 0.5 to 1.0 for the period before the early 1980s and from 1.0 to 2.0 for the period thereafter (Fig. 1). A similar situation is found for the frequency of the high PMV values (PMV $\geq 2$ ). From the 1950s until the early 1980s, the seasonal number of discomfort days generally ranges from 20 to 40 , while in the last $30 \mathrm{yr}$ this number is higher and ranges from 40 to 80 , exceeding $60 \%$ of summer days in the latter years of the study period. For the light wind conditions, the values are lower, as expected, but for the last 10-12 yr of the study period they exceed values typical of the few first years displayed for calm conditions. An opposite (negative) trend is shown for number of days with low PMV values less than -2 , but the decrease (also statistically significant) is not so strong (Fig. 2). Also of note for the situation of light winds is that the late 1980s represents a transition from a period when, in an absolute sense, conditions of cool-related discomfort dominated to a period when heat-related discomfort is a distinct feature of Athens thermal climate. From a thermal comfort management perspective, this is important as periods of cool-related discomfort can be coped with more readily than those for heat-related discomfort. The increase in human thermal dis-

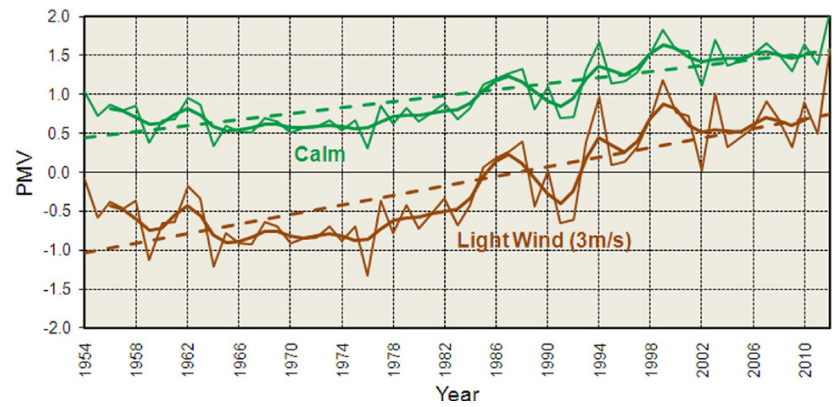

Fig. 1. Inter-annual variation of mean summer (1 May-30 September) PMV values for Athens at 14:00 for calm and light wind conditions. The curves are smoothed (bold lines) using five-year moving averages with binomial coefficient weights. The dashed lines indicate the statistically significant (95\% confidence level) linear trends.

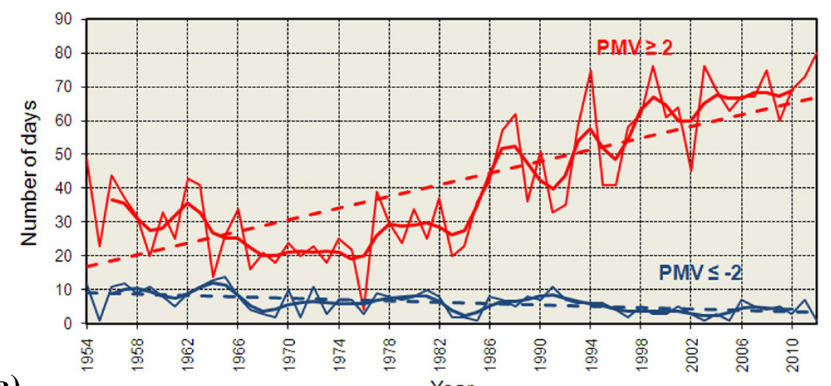

(a)

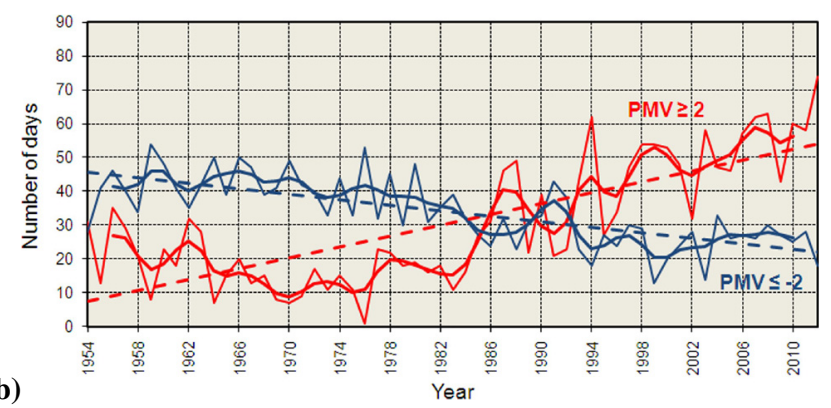

Fig. 2. Inter-annual variation of the number of summer (1 May30 September) days of discomfort (PMV $\geq 2$ and $P M V \leq-2)$ for Athens at 14:00 for the period 1954-2012 (a) for calm and (b) for light wind conditions (smoothing and trends as in Fig. 1).

comfort noted here for Athens after the early 1980s matches with similar trends during the same period found by others either for mean summer air temperature or for the frequency of extreme high temperature events, which have been reported to be a result of the predominance of warmer air masses in the lower troposphere over the southern Balkans and the intensification of urbanization in the city of Athens over recent years (e.g. see Philandras et al., 1999; Lolis et al., 2002; Kioutsioukis et al., 2010; Founda, 2011).

The inter-annual variations of the dates of onset and cessation of discomfort (PMV $\geq 2$ ) as well as the corresponding duration of discomfort are shown in Figs. 3 and 4. The 
(a)

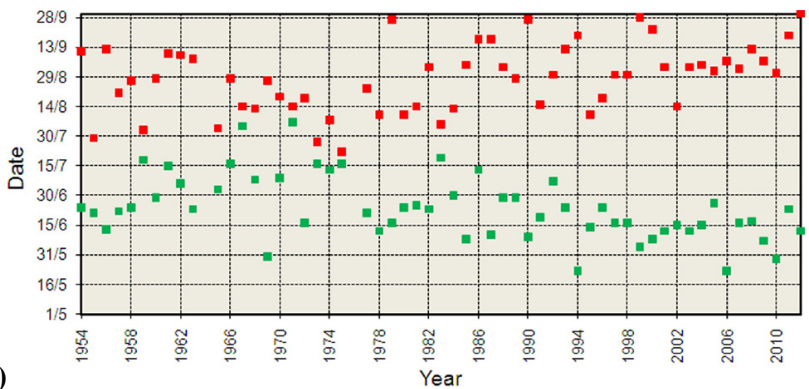

(b)

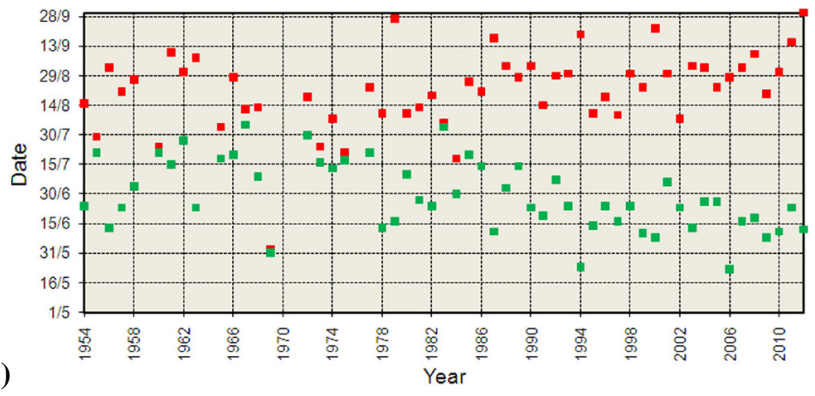

Fig. 3. Dates of onset (green squares) and cessation (red squares) of PMV $\geq 2$ discomfort in Athens at 14:00 for (a) calm and (b) light wind conditions. No discomfort period occurred for the years 1964 and 1976 for calm and 1959, 1964, 1970, 1971, and 1976 for light wind conditions.

characteristics of the inter-annual variations are in agreement with the above results for discomfort intensity and frequency. Specifically, before the early 1980s the onset of the discomfort period was around the beginning of July and cessation around the end of August, but after the early 1980s the dates of onset and cessation have shifted earlier (middle June) and later (middle September), respectively, leading to a longer summer discomfort period. This is in agreement with the already mentioned positive trends in the mean seasonal PMV values and the frequency of high PMV days. For calm conditions, the mean discomfort duration is about 40 days for the period before the early 1980s and about 80 days for recent years. A positive statistically significant trend is found for the variation of discomfort duration for both calm and light wind conditions. The above trends are in agreement with ongoing climate change, which is associated with a continuous increase in the frequency of heat waves in southeastern Greece (Giannakopoulos et al., 2011; Matzarakis and Nastos, 2011).

The intra-seasonal variations of (i) the $59 \mathrm{yr}$ mean daily 14:00 PMV values and its standard deviation and (ii) the percentage of discomfort cases for each calendar day (the percentage of years presenting discomfort at 14:00 for each summer day) are presented in Figs. 5 and 6. Mean daily 14:00 PMV values reach a maximum during the high-summer months of July and August as do the percentage of PMV $\geq$ 2 discomfort cases (years). For calm conditions, the mean 14:00 PMV values are close to the upper discomfort thresh-

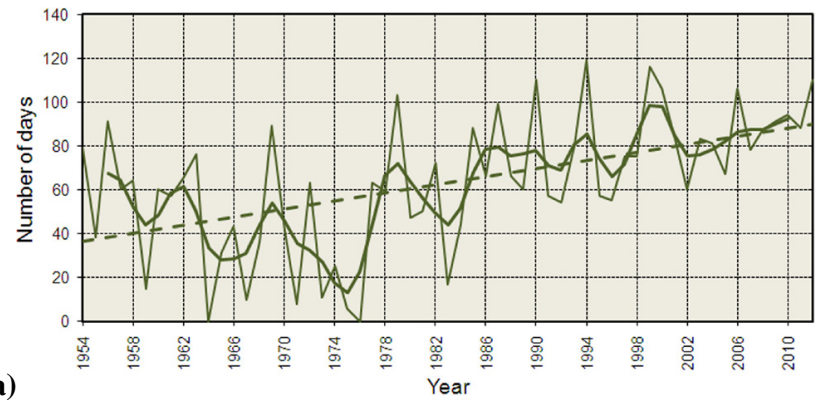

(a)

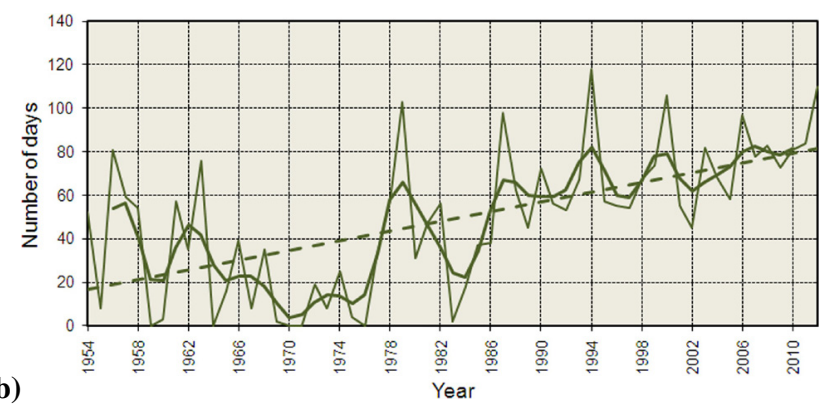

Fig. 4. Inter-annual variation of duration of $P M V \geq 2$ summer discomfort in Athens at 14:00 for (a) calm and (b) light wind conditions for the period 1954-2012 (smoothing and trends as in Fig. 1).

old (PMV = 2) from early July to middle August, while the percentage of discomfort cases ranges from $40 \%$ to more than $60 \%$ during the same period. On the other hand, the percentage of PMV $\leq-2$ discomfort days is practically zero from early June to the end of August, while it is considerable (above $10 \%$ ) only before 20 May. The intra-seasonal variation of standard deviation of PMV (Fig. 5b) shows lower values during high summer as might be expected due to the persistence of settled weather conditions.

The connection between human thermal discomfort in Athens and atmospheric circulation for the period 1954 1999 is investigated by evaluating the distribution of PMV statistics across six objectively defined circulation types for the warm period of the year as identified by Kassomenos et al. (2003) for the Athens area. The mean sea level pressure patterns for the six circulation types are presented in Fig. 7. The distribution of discomfort cases across the circulation types is shown in Fig. 8 and reveals that $P M V \geq 2$ discomfort conditions prevail mainly under circulation types 3 and 4 . Also evident is that, for a person not exposed to wind (calm conditions) during weather events associated with circulation types 3 and 4, discomfort at 14:00 would be experienced on $44 \%$ and $36 \%$ of days respectively. PMV $\leq-2$ discomfort conditions are associated mainly with the other four circulation types. Circulation types 3 and 4 are frequent during the summer (26\% and $17 \%$ of the days respectively) but dominate during July and August (49\% and $40 \%$ respectively) (Table 1). The other types present maximum frequency either 
Table 1. Occurrence frequency of circulation types, maximum air temperature, daily relative humidity and 14:00 PMV values in Athens during summer (1 May-30 September).

\begin{tabular}{ccccccccc}
\hline $\begin{array}{c}\text { Circulation } \\
\text { type }\end{array}$ & $\begin{array}{c}\text { Occurrence } \\
(\%)\end{array}$ & $\begin{array}{c}\text { Occurrence for } \\
\text { July-August } \\
(\%)\end{array}$ & $\begin{array}{c}\text { Maximum } \\
\text { temperature } \\
\left({ }^{\circ} \mathrm{C}\right)\end{array}$ & $\begin{array}{c}\text { Relative } \\
\text { humidity } \\
(\%)\end{array}$ & $\begin{array}{c}\text { PMV } \\
(\text { calm })\end{array}$ & $\begin{array}{c}\text { St. Dev. } \\
\text { of PMV } \\
(\text { calm })\end{array}$ & $\begin{array}{c}\text { PMV } \\
\text { (light wind) }\end{array}$ & $\begin{array}{c}\text { St. Dev. } \\
\text { of PMV } \\
(\text { light wind })\end{array}$ \\
\hline 1 & 15 & 4 & 25.3 & 64 & -0.21 & 1.40 & -2.14 & 2.27 \\
2 & 9 & 3 & 25.0 & 52 & -0.24 & 1.47 & -2.14 & 2.38 \\
3 & 26 & 49 & 32.5 & 51 & 1.85 & 1.04 & 1.24 & 1.69 \\
4 & 17 & 40 & 31.7 & 45 & 1.61 & 1.05 & 0.87 & 1.72 \\
5 & 19 & 3 & 27.5 & 59 & 0.48 & 1.13 & -1.00 & 1.85 \\
6 & 14 & 1 & 24.3 & 57 & -0.59 & 1.15 & -2.73 & 1.87 \\
\hline All cases & & & 28.5 & 54 & 0.85 & 1.51 & -0.38 & 2.46 \\
\hline
\end{tabular}

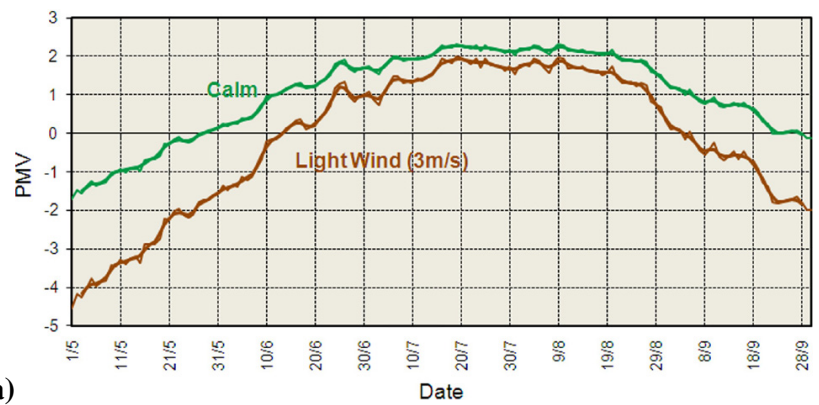

(a)

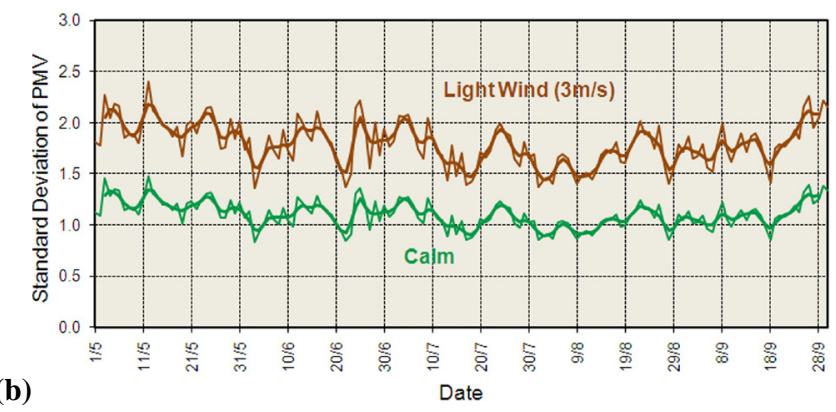

Fig. 5. Mean intra-seasonal (1 May-30 September) variation of (a) PMV and (b) PMV standard deviation in Athens at 14:00 for calm and light wind conditions for the period 1954-2012 (smoothing as in Fig. 1).

at the beginning or at the end of the warm period (figure not shown). The average summer maximum temperature, relative humidity and 14:00 PMV values along with their standard deviations, for each circulation type, are also given in Table 1. Circulation types 3 and 4 present the highest PMV values with the lowest standard deviations, which indicate nearly steady or persistent weather conditions. Therefore, we will focus on these two types inasmuch as they can be considered as the typical high-summer pressure patterns. Both types are characterised by the presence of a summer thermal low over SW Asia and high pressure values over Europe. Their differences appear in the position and the intensity of the anticyclone centre and the pressure gradient over

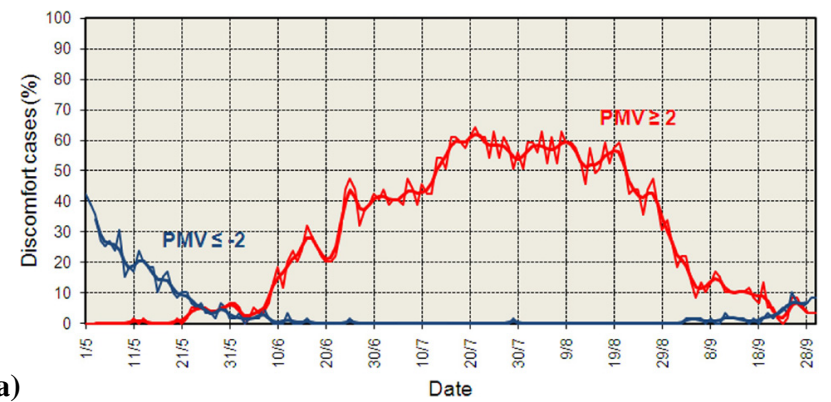

(a)

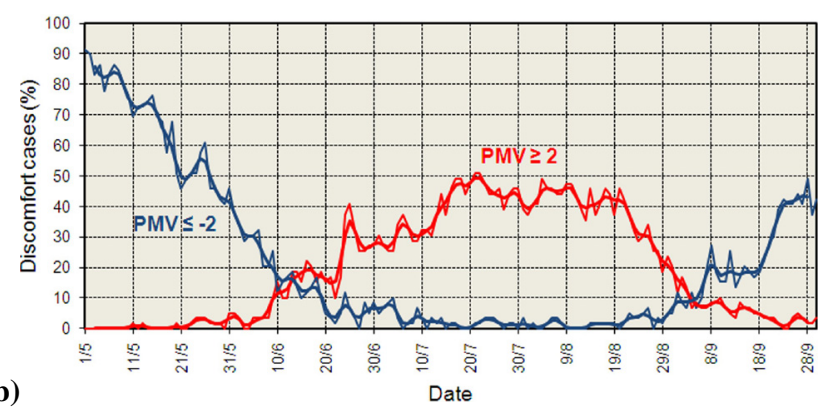

Fig. 6. Mean intra-seasonal (1 May-30 September) variation of discomfort frequency at 14:00 in Athens for (a) calm and (b) light wind conditions, for the period 1954-2012 (smoothing as in Fig. 1).

the Aegean Sea. The pattern of type 4 can be considered as a typical Etesian wind pattern (e.g. see Metaxas and Bartzokas, 1994; Ziv et al., 2004), while in type 3 the Etesian winds over the Athens area appear to be weaker in a relative sense. In the Aegean in summer, a powerful sea breeze system dominates superimposed on which are the northerly Etesian winds. In Athens the sea breeze blows from the south opposing the Etesian winds. Days associated with this opposing wind system have been defined as "Etesian" and "sea breeze" days (Carapiperis, 1951) depending on the dominant wind direction at noontime. In terms of human thermal comfort, the Etesian winds are an important climatological feature because they moderate the summer heat, as this wind is cool and dry over 

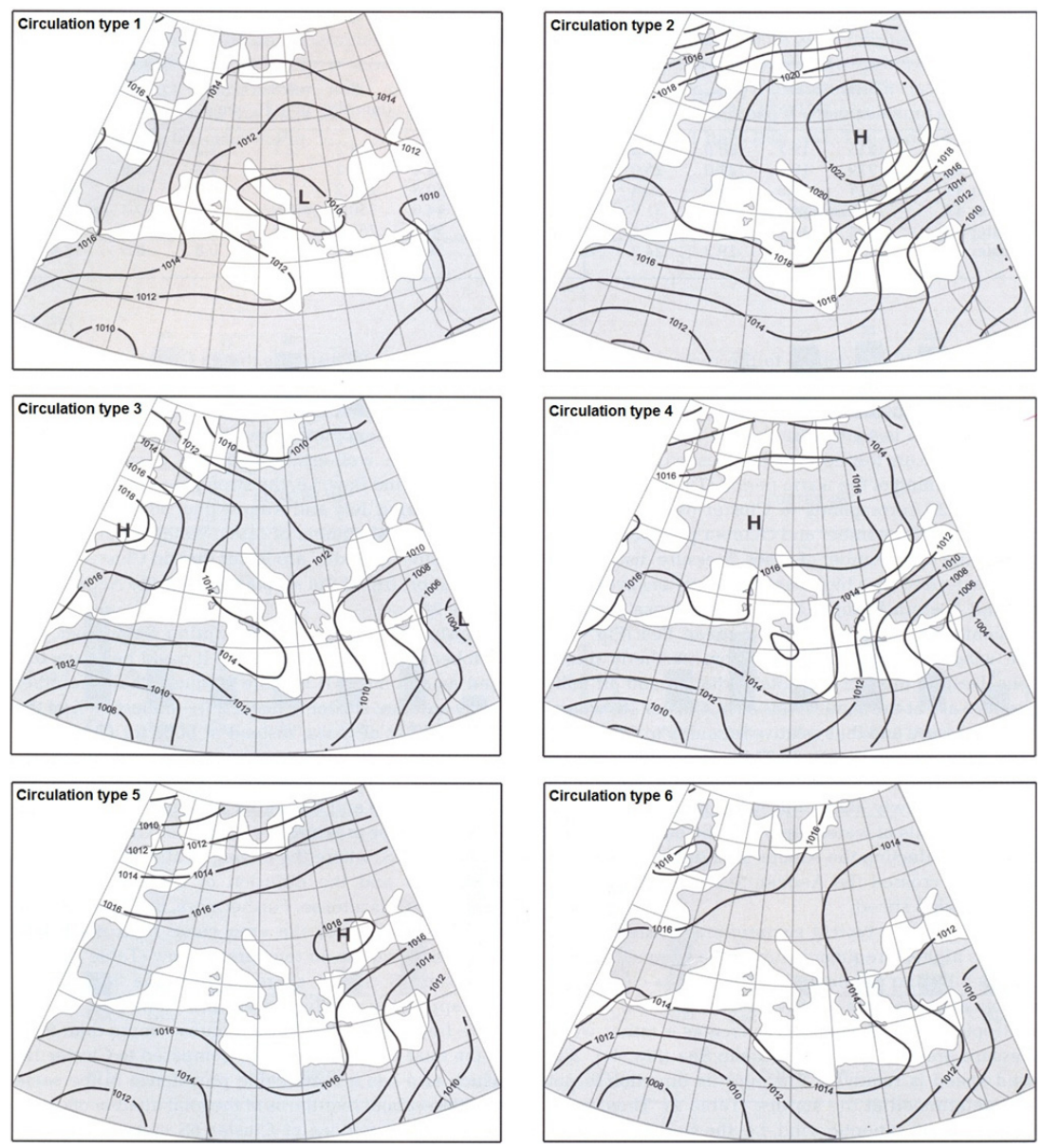

Fig. 7. The 6 circulation types over Europe, defined by Kassomenos et al. (2003) based on the Athens weather in the warm period.

the Aegean and adjacent areas. They also affect tourism and sailing and disperse pollutants, which build up when the sea breeze prevails along with a strong inversion. Based on the above and comparing the pressure patterns for circulation types 3 and 4, we suggest that "sea breeze" days are more frequently associated with type 3 while "Etesian" days are a feature of type 4. This is in agreement with the highest PMV values in Table 1, which appear for circulation type 3. Further insights into atmospheric conditions that bear implications for thermal comfort are gained if the average water-vapour pressure is considered for calm conditions associated with circulation types 3 and 4 . For type 3 , water-vapour pressure is found to be $24 \mathrm{hPa}$ while for type 4 it is lower at $21 \mathrm{hPa}$. Taking also into account the higher maximum temperature and relative humidity values for circulation type 3 days (Table 1), we suggest that discomfort can be expected to be higher on type 3 days. However it should be remembered that this assertion applies for the situation of a person sitting in a place sheltered from the sun and not exposed (or exposed slightly) to the wind. Therefore, these results are valid only for people not exposed to moderate to strong summer breeze winds or the Etesian wind.
The inter-annual variations of discomfort intensity and frequency for circulation types 3 and 4 are presented in Figs. 9 and 10 respectively. Of note are the upward trends of discomfort intensity and frequency for both circulation types; all linear trends are statistically significant. Comparing Fig. 9 with Fig. 1 (for the common period 1954-1999), we see that PMV values for circulation types 3 and 4 are higher than the ones for all cases, as expected. More specifically, for calm conditions, for circulation type 3/4, all 46/40 values are higher than the summer climatological values with the differences ranging from $0.2 /-0.1$ to $1.0 / 0.9$ and the average difference being $0.55 / 0.27$. Similar results are found for light wind conditions. It is noted that during the last summers of the 20th century, when circulation type 3 prevails, the discomfort threshold, 2 , is exceeded even by the average PMV value. In Fig. 10, the annual days with PMV $\geq 2$ are presented as percentages on the $y$-axis (since the number of days characterised by each circulation type is not the same every year). This reveals that the increase of discomfort frequency is more evident after the early 1980s, especially for circulation type 4, since the percentage of high PMV discomfort days doubled. In other words, it appears that, during the last years of the 


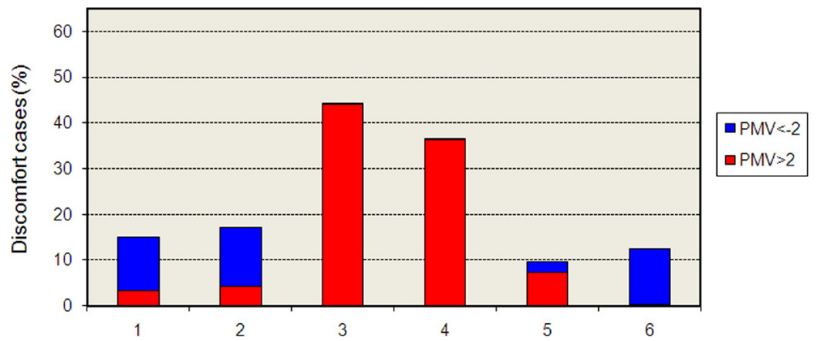

(a)

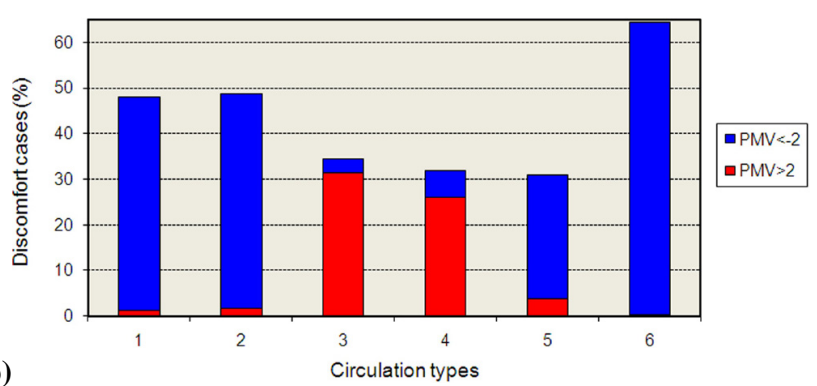

Fig. 8. Percentage of discomfort cases in Athens at 14:00 for the 6 circulation types defined by Kassomenos et al. (2003), for (a) calm and (b) light wind conditions.

20th century, Athenians experienced discomfort regardless of whether circulation type 3 or 4 prevailed. It is also noted that the above increase is not related to the frequency of occurrence of the two types as it refers only to the days of their prevalence. In any case, Kassomenos et al. (2003) did not find any statistically significant increase or decrease of the occurrence frequency of the two circulation types.

\section{Conclusions}

The main characteristics of the inter-annual and the intraannual variability of summer human thermal discomfort in the Athens area have been examined and revealed the following for a person, lightly dressed, sitting in a place sheltered from the sun and not exposed to strong wind:

1. There is a significant increase in the intensity and the frequency of summer human thermal discomfort in Athens after the early 1980s. The frequency of high discomfort days has doubled during the same period.

2. Before the early 1980s the onset of the discomfort period takes place around the beginning of July and cessation around the end of August, but after early 1980s the dates of onset and cessation have shifted earlier (middle June) and later (middle September), respectively, leading to a longer summer discomfort period.

3. From early July to middle August, the discomfort levels are close to the upper discomfort threshold, while during this period more than $50 \%$ of the days are characterised by high discomfort levels.

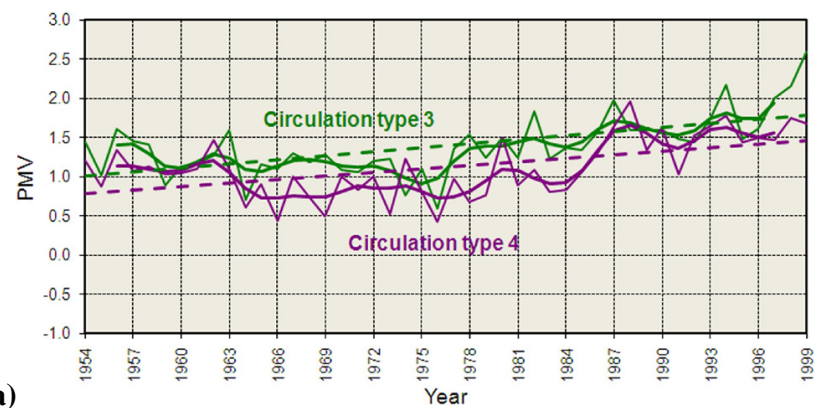

(a)

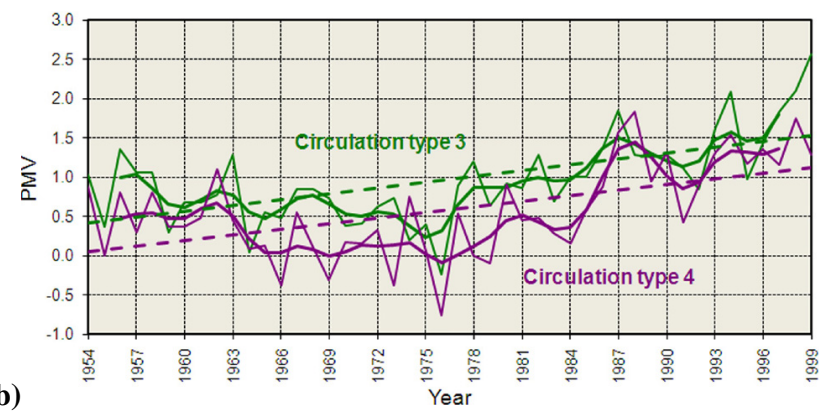

Fig. 9. As in Fig. 1 but for circulation types 3 and 4 and for the period 1954-1999.

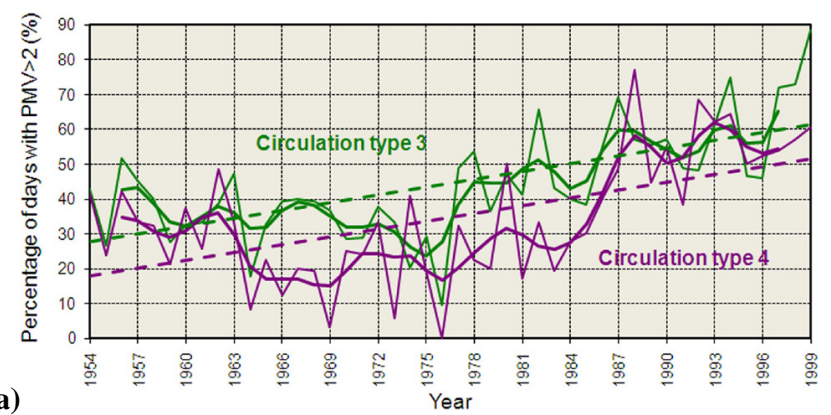

(a)

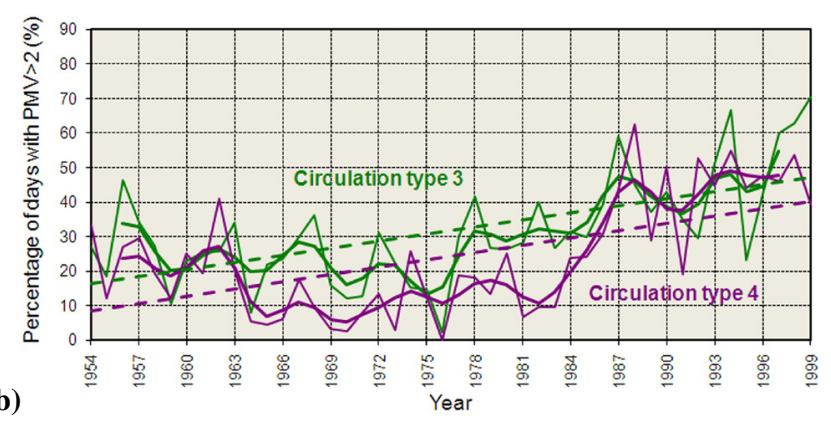

Fig. 10. As in Fig. 2 but for circulation types 3 and 4 and in percentages (\%) and for the period 1954-1999.

4. Days characterised by strong Etesian winds are associated with less heat-related discomfort until the 1980s, after which it appears that urbanization and climate change tend to eliminate this influence as manifested by an increasing frequency of days with high PMV index values. 
Results bear implications for heat risk management in Athens especially as this study has demonstrated at an intra-seasonal time scale when the period of severe discomfort occurs on a climatological basis. Further, the identification of the largescale atmospheric circulation conditions associated with periods of high levels of thermal discomfort may assist with the development of weather-based early warning systems for heat stress. The fact that there is compelling statistical evidence that points to a significant change in levels of discomfort and the duration of the season of discomfort raises the question as to whether the detected trends in discomfort can be attributed to human-induced climate change. While answering this question is beyond the scope of this study, findings presented here lay the basis for assessing the role of anthropogenic climate change in altering levels of human thermal comfort. Lastly, the analyses undertaken here have raised a number of questions about the thermal comfort climatology of Athens. What are the levels of human thermal stress for fully exposed/non-sheltered conditions taking into account solar radiation loading and different wind speed scenarios? What is the cause and nature of extreme thermal discomfort events and their associated temporal behaviour and to what extent might the urban heat island effect raise levels of discomfort beyond those due to regional/global warming? Such questions provide a basis for further work on Athens human thermal climate.

Acknowledgements. The data used in this work have been kindly provided by the National Observatory of Athens.

Edited by: G. Boni

Reviewed by: three anonymous referees

\section{References}

Bartzokas, A. and Metaxas, D. A.: Climatic fluctuation of temperature and air circulation in the Mediterranean, Environment and quality of life, in: Climate and global change (Proceedings of the European School of Climatology and Natural Hazards course), Arles/Rhone, France, April 1990, 279-297, 1991.

Blazejczyk, K., Epstein, Y., Jendritzky, G., Staiger, H., and Tinz, B.: Comparison of UTCI to selected thermal indices, Int. J. Biometeorol., 56, 515-535, doi:10.1007/s00484-011-0453-2, 2012.

Carapiperis, L. N.: On the periodicity of Etesian in Athens, Weather, 6, 379-379, doi:10.1002/j.1477-8696.1951.tb01292.x, 1951.

de Freitas, C.: Recreation climate assessment, Int. J. Climatol., 10, 89-103, doi:10.1002/joc.3370100110, 1990.

Fanger, P. O.: Thermal comfort, analysis and applications in environmental engineering, McGraw-Hill, New York, 1972.

Fiala, D., Havenith, G., Bröde, P., Kampmann, B., and Jendritzky, G.: UTCI-Fiala multi-node model of human heat transfer and temperature regulation, Int. J. Biometeorol., 56, 429-441, doi:10.1007/s00484-011-0424-7, 2012.

Founda, D.: Evolution of the air temperature in Athens and evidence of climatic change: A review, Advances in Building Energy Research, 5, 7-41, doi:10.1080/17512549.2011.582338, 2011.
Fountain, M. E. and Huizenga, C.: WINCOMF: a Windows 3.1 thermal sensation model user's manual for Wincomf, Environmental Analytics, Berkeley, CA, 1995.

Giannakopoulos, C., Kostopoulou, E., Varotsos, K. V., Tziotziou, K., and Plitharas, A.: An integrated assessment of climate change impacts for Greece in the near future, Reg. Environ. Change, 11, 829-843, doi:10.1007/s10113-011-0219-8, 2011.

Giles, B. D., Balafoutis, C., and Maheras, P.: Too hot for comfort: the heat waves in Greece in 1987 and 1988, Int. J. Biometeorol., 34, 98-104, doi:10.1007/BF01093455, 1990.

Hoppe, P.: Heat balance modeling, Experientia, 49, 741-746, doi:10.1007/BF01923542, 1993.

Houghten, F. C. and Yaglou, C. P.: Determining lines of equal comfort, Journal of American Society of Heating and Ventilating Engineers (ASHVE) Trans, 29, 163-176, 1923.

Jauregui, E.: The human climate of tropical cities an overview, Int. J. Biometeorol., 35, 151-160, doi:10.1007/BF01049061, 1991.

Jendritzky, G., de Dear, R., and Havenith, G.: UTCI-Why another thermal index?, Int. J. Biometeorol., 56, 421-428, doi:10.1007/s00484-011-0513-7, 2012.

Kassomenos, P. A., Sindosi, O. A., and Lolis, C. J.: Seasonal variation of the circulation types occurring over southern Greece: A 50-year study, Clim. Res., 24, 33-46, 2003.

Kioutsioukis, I., Melas, D., and Zerefos, C.: Statistical assessment of changes in climate extremes over Greece (1955-2002), Int. J. Climatol., 30, 1723-1737, doi:10.1002/joc.2030, 2010.

Lolis, C. J., Bartzokas, A., and Katsoulis, B. D.: Spatial and temporal $850 \mathrm{hpa}$ air temperature and sea-surface temperature covariances in the Mediterranean region and their connection to atmospheric circulation, Int. J. Climatol., 22, 663-676, doi:10.1002/joc.759, 2002.

Matzarakis, A. and Mayer, H.: Heat stress in Greece, Int. J. Biometeorol., 41, 34-39, doi:10.1007/s004840050051, 1997.

Marzarakis, A. and Nastos. P. T.: Human-biometeorological assessment of heat waves in Athens, Theor. Appl. Climatol., 105, 99106, doi:10.1007/s00704-010-0379-3, 2011.

Mavrakis, A., Spanou, A., Pantavou, K., Katavoutas, G., Theoharatos, G., Christides, A., and Verouti, E.: Biometeorological and air quality assessment in an industrialized area of eastern Mediterranean: The Thriassion Plain, Greece, Int. J. Biometeorol., 56, 737-747, doi:10.1007/s00484-011-0475-9, 2012.

McGregor, G. R.: The human bioclimates of western and south Pacific islands and climate change, Int. J. Biometeorol., 39, 5-12, doi:10.1007/BF01320886, 1995a.

McGregor, G. R.: Theoretical current and future indoor thermal preferendum for equatorial western and tropical South Pacific, Theor. Appl. Climatol., 50, 227-234, doi:10.1007/BF00866119, $1995 b$.

McGregor, G. R.: Human biometeorology, Prog. Phys. Geog., 36, 93-109, doi:10.1177/0309133311417942, 2011.

McGregor, G. R., Markou, M. T., Bartzokas, A., and Katsoulis, B. D.: An evaluation of the nature and timing of summer human thermal discomfort in Athens, Greece, Clim. Res., 20, 83-94, doi:10.3354/cr020083, 2002.

Metaxas, D. A.: Biometeorological indices and climatization in Greece during summer, Technika Cronika (publ. of the Technical Chamber of Greece), 6, 321-332, 1970 (in Greek).

Metaxas, D. A. and Bartzokas, A.: Pressure covariability over the Atlantic, Europe and N. Africa. application: Centers 
of action for temperature, winter precipitation and summer winds in Athens, Greece, Theor. Appl. Climatol., 49, 9-18, doi:10.1007/BF00866284, 1994.

Metaxas, D. A., Bartzokas, A., and Vitsas, A.: Temperature fluctuations in the Mediterranean area during the last 120 years, Int. J. of Climatol., 11, 897-908, doi:10.1002/joc.3370110808, 1991.

Nastos, P. T. and Matzarakis, A.: The effect of air temperature and human thermal indices on mortality in Athens, Greece, Theor. Appl. Climatol., 108, 591-599, doi:10.1007/s00704-011-05550,2012

Pantavou, K., Theoharatos, G., Nikolopoulos, G., Katavoutas, G., and Asimakopoulos, D.: Evaluation of thermal discomfort in Athens territory and its effect on the daily number of recorded patients at hospitals' emergency rooms, Int. J. Biometeorol., 52, 773-778, doi:10.1007/s00484-008-0170-7, 2008.
Philandras, C. M., Metaxas, D. A., and Nastos, P. T.: Climate variability and urbanization in Athens. Theor. Appl. Climatol., 63, 65-72, doi:10.1007/s007040050092, 1999.

Thom, E. C.: The discomfort index, Weatherwise, 12, 57-60, doi:10.1080/00431672.1959.9926960, 1959.

Vouterakos, P. A., Moustris, K. P., Bartzokas, A., Ziomas, I. C., Nastos, P. T., and Paliatsos, A. G.: Forecasting the discomfort levels within the greater Athens area, Greece using artificial neural networks and multiple criteria analysis, Theor. Appl. Climatol., 110, 329-343, doi;10.1007/s00704-012-0626-x, 2012.

Yarnal, B.: Synoptic Climatology in Environmental Analysis, New York, John Wiley and Sons, 1993.

Ziv, B., Saaroni, H., and Alpert, P.: The factors governing the summer regime of the eastern Mediterranean, Int. J. Climatol., 24, 1859-1871, doi:10.1002/joc.1113, 2004. 